\title{
Expression of heat shock protein (HSP) genes and antioxidant enzyme genes in hybrid rice II YOU 838 during heat stress
}

\author{
Yan Wang ${ }^{1,2}$, Min Huang ${ }^{2}$, Peng Gao ${ }^{2}$, Hao Chen ${ }^{2}$, Yu Zheng ${ }^{2}$, Chenming Yang ${ }^{2}$, Zhirong Yang ${ }^{1}$, \\ Qun Sun
}
${ }^{1}$ Key Laboratory of Bio-resource and Bio-environment of the Ministry of Education, College of Life Science, Sichuan University, Chengdu, Sichuan 610064, P.R. China
${ }^{2}$ Key Laboratory of Irradiation Preservation of Sichuan Province, Sichuan Institute of Atomic Energy, Chengdu, Sichuan 610066, P.R. China

\section{*Corresponding author: qunsun@scu.edu.cn}

\begin{abstract}
II YOU 838 (Oryza sativa subsp. indica), crossed by the maternal II-32A and paternal Fu Hui 838, was one of the most widely cultivated hybrid rice in China. Fu Hui 838, which has resistance to high temperature, was generated by mutation technology in 1990. Previous fieldtesting showed that II YOU 838 had tolerance to high temperature stress and this was confirmed in the present study. The mechanism of heat tolerance of II YOU 838 is not understood. The present study reports gene expression of a representative sample of heat-responsive proteins in II YOU 838 flag leaves subjected to heat stress during flowering. Differential expression of the heat shock protein 70 (HSP70), heat shock protein 90 (HSP90), small heat shock protein (smHSP), superoxide dismutase (SOD), catalase (CAT) and peroxidase (POD) were studied under heat stress and optimum temperatures in flag leaves of II YOU 838. All six genes studied were responsive to high temperatures. Quantitative real-time PCR showed increased expression of the heat shock protein genes and antioxidant enzyme genes in flag leaves under heat stress. With increasing number of days gene expression decreased under high temperature. Peak expression of $S O D$, $P O D$, $h s p 70$ and $h s p 90$ was on Day 2 under $39^{\circ} \mathrm{C}$. On Day 3 , the expression of $C A T$ under $39{ }^{\circ} \mathrm{C}$ was the highest. The expression of $s m b s p$ was highest on Day 3 under $27^{\circ} \mathrm{C}$, followed by that on Day 2 under $27^{\circ} \mathrm{C}$. The maximum expression values were observed on Day 2 or Day 3 after beginning of heat stress. This suggests that $h s p 90, h s p 70$, SOD and POD are principally involved in early responses to heat in rice flag leaves, and that $s m h s p$ may play a role in the recovery mechanism in rice after heat stress. This may provide insights into the mechanism of heat-tolerance in rice.
\end{abstract}

Key Words: II YOU838; antioxidant enzyme; hybrid rice; high-temperature stress; heat shock protein; quantitative real time-PCR Abbreviation: SSH_Suppression subtractive hybridization; RT-PCR_ Reverse transcription polymerase chain reaction; HSPs_ Heat shock proteins; ROS_Reactive oxygen species; SOD_Superoxide dismutase; CAT_Catalase; POD_Peroxidase.

\section{Introduction}

High temperature is considered as one of the major stresses in crop production (Grover et al. 2000). Rice is very sensitive to high-temperature stress at almost all the stages of growth and development, especially anthesis is the most susceptible stage. Suppression subtractive hybridization (SSH) allows genes involved in heat stress response to be identified and their activity monitored (Huang et al. 2009). The smbsp, hsp70, and hsp90, SOD, $P O D$ and $C A T$ genes were differentially expressed by $\mathrm{SSH}$. Several stresses induce the production of a group of proteins called heat shock proteins (HSPs) (Chandel et al. 2013). It has been suggested that HSPs, as molecular chaperones, regulate the folding and accumulation of proteins as well as their localization and degradation in plants ( (Hu et al. 2009; Sottile and Nadin 2018). HSPs protect other proteins from damage and participate in re-folding proteins, thus ensuring the maintenance of correct protein structure during heat stress conditions (Panaretou and Zhai 2008). HSPs protect cells from injury and facilitate recovery and survival after a return to normal growth conditions. The HSPs in plants are grouped into HSP100, HSP90, HSP70, HSP60, HSP40 and smHSPs families according to their molecular weight, amino acid sequence homologies and functions (Gupta et al. 2010). It is believed that the diversification of these proteins reflects an adaptation to heat stress. HSP70, smHSPs and HSP90 proteins are the predominant forms of chaperones expressed under high temperature stress conditions (Wang et al. 2004). HSP70 is a cytosolic chaperone which facilitates protein folding, degradation, complex assembly, and translocation, as well as assembly and disassembly of multimeric structure in plants (Chen et al. 2017). HSP70 may also suppress programmed cell death in rice protoplasts (Qi et al. 2011). The smHSPs may prevent irreversible aggregation of partially unfolded or denatured proteins by binding to hydrophobic sites on their surface to maintain them in a refoldable conformation (Baniwal et al. 2004; Chen et al. 2014; Smykal et al. 2000). HSP90 is a highly conserved molecular chaperone contributing to the folding, maintenance of structural integrity and proper regulation of a subset of cytosolic proteins (Csermely et al. 1998; Young et al. 2001). The most well-known function of HSP90 is its involvement in the maintenance of key proteins such as steroid receptors and protein kinases by forming specific complexes. The heat shock response is characterized by a rapid and robust increase in HSPs upon exposure to proteindamaging stresses. 
This evolutionarily conserved cellular protection mechanism is primarily regulated at the level of transcription (Hietakangas and Sistonen 2006). The transcriptional responses of the different HSPs to different intensities of heat stress are unclear. The aim here is to compare their expression under a range of heat stress treatments, in order to gain a better understanding of their response to heat stress in rice.

Exposure to heat stress can give rise to excessive accumulation of reactive oxygen species (ROS) in plant cells (Cheng et al. 2007; Zhao et al. 2018). ROS are potentially harmful to the cell, as they can raise the level of oxidative damage through loss of cellular structure and function. Cells possess antioxidants and antioxidative enzymes to interrupt the cascades of uncontrolled oxidation in cellular organelles. Among the antioxidative enzymes, superoxide dismutase (SOD), catalase (CAT) and peroxidase (POD) play key roles in detoxification. SOD, the first enzyme in the detoxifying process, converts superoxide anion radicals $\left(\mathrm{O}_{2}{ }^{-}\right)$to hydrogen peroxide $\left(\mathrm{H}_{2} \mathrm{O}_{2}\right)$, then POD and CAT reduces $\mathrm{H}_{2} \mathrm{O}_{2}$ to water (Asada 1999). $\mathrm{H}_{2} \mathrm{O}_{2}$ is an important signal molecule in the signal transmission network of many stresses. Previous work has demonstrated that CAT functions in plant disease, heat, water, salt, and light stress reactions. The homeostasis of $\mathrm{H}_{2} \mathrm{O}_{2}$ is mostly due to CAT scavenging and regulating functions. How SOD, POD and CAT genes regulate the various aspects of heat damage is still unclear, but the information accumulated so far is a promising starting point for further studies to identify their functions and to investigate potential applications / targets, e.g. in molecular plant breeding. II YOU 838 exhibited superiority for multiple agronomic traits, including yield, wide adaptability, especially the resistance to high temperatures, thus it has been widely cultivated in China (Su et al. 2013; Wang et al. 2016). Its pedigree goes back to the rice restorer line, Taiying I hao, which was irradiated with ${ }^{60} \mathrm{Co}$ gamma-rays in 1976 (Deng et al. 2009). The mutant rice cultivar Fuhui 06 was obtained by selection in the fourth mutant generation $\left(\mathrm{M}_{4}\right)$. Fuhui 06 was crossed with glutinous rice 80182 in 1982 to obtain the glutinous rice restorer line 226, selected in the 5 th generation $\left(M_{5}\right)$. Seed of the rice restorer line Minghui 63 were irradiated with $380 \mathrm{~Gy}{ }^{60} \mathrm{Co}$ gamma-rays in 1984 to develop the mutant rice cultivar $\gamma 552$ by selection at varying temperatures in artificial climate chambers. In 1990, the Fu Hui 838, which was selected from the sixth generation $\left(\mathrm{M}_{6}\right)$, was crossed with a maternal mutation rice $(\gamma 552)$ and paternal mutation rice (226). Fu Hui 838 was bred and released by combined techniques of radiation induced mutation, conventional hybridization, and temperature tolerance screening. Fu Hui 838, which is a major restorer line in China, it has good resistance and produces good vigour in hybrids when crossed with certain rice lines. II YOU 838, which was crossed by II-32A as female parent and Fu Hui 838 as male parent, was examined and approved by the Sichuan provincial variety committee in the Sichuan Institute of Atomic Energy in 1995.

The objective of the present study was to evaluate the expression patterns of $h s p 90$, hsp70, smhsp, SOD, POD and CAT in II YOU 838 at different heat-stress intensities, and to evaluate the potential of these genes as heat resistance molecular biomarkers. If there is a correspondence between the heat resistance /injury and the expression of these genes, we can analyze the expression of these genes to clarify the degree of heat stress in rice. There are many studies involving these genes, but insufficient data to prove that these genes can be used as molecular bio-markers for rice heat stress in field. This may provide a better understanding of the molecular mechanisms involved in heat tolerance and may facilitate the development of heat-tolerant rice cultivars.

\section{Results}

Standard curve development of hsp90, hsp70, smhsp, SOD, $P O D$ and $C A T$

Gel-electrophoresis and a melting curve analysis of PCR products showed that very little or no primer-dimers or other non-specific amplification products were generated during the runs. Ten-fold serial PCR product dilutions were tested and used to construct the standard curve by plotting the PCR products. The generated standard curve covered a linear range of $1 \times 10^{2}$ to $1 \times 10^{8}$ copies per reaction for smbsp, hsp70, hsp90, POD, SOD, $C A T, 18 s \mathrm{rRN} A$ and actin-1. Samples were repeated three times. The average mean of the three PCR reaction efficiencies was used. The efficiency of the reaction of $18 \mathrm{~s} r \mathrm{R} N A$ primers, actin-1 primers, smhsp primers, hsp90 primers, hsp70 primers, SOD primers, $P O D$ primers and $C A T$ primers was $87.2 \%, 97.3 \%$, $76.4 \%, 82.9 \%, 84.2 \%, 92 \%, 88.9 \%, 95.4 \%$, respectively. The standard curves are credible when the $\mathrm{R}^{2}>0.980$, so the standard curves of the five genes are considered credible.

\section{Expression of hsp70, hsp90 and smhsp genes after heat treatment}

During the flowering stage, both the heat treatment group and the control group samples were collected over 24-h intervals for four days. Samples for the heat-stress treatment of $27{ }^{\circ} \mathrm{C}$ were collected at 08:00 $\mathrm{h}$ and those for $39{ }^{\circ} \mathrm{C}$ were collected at 16:00 h. We compared the expression of HSPs between the heat treatment group and the control group by quantitative real-time RT-PCR. The results were normalized against the mean for the reference genes. The normalized expression of $h s p 70$, hsp90 and smbsp were significantly increased after heat treatment (Fig. 1), and higher than the control group samples and that of samples before heat treatment. There were significant differences between the heat treatment group and the control group $(p<$ $0.05)$, except in case of the $39{ }^{\circ} \mathrm{C}$ heat treatment group of $h s p 70$ and $h s p 90$ at Day 4. There was no significant difference in the expressions of $s m h s p, h s p 70$ and $h s p 90$ among the control group from Day 1 to Day 4. After heat treatment, the expressions of bsp70 and $h s p 90$ under $39^{\circ} \mathrm{C}$ on Day 2 were the highest of any other heat treatment group sampled under $39{ }^{\circ} \mathrm{C}$. The expression of smbsp under $27^{\circ} \mathrm{C}$ on Day 3 was the highest of any other heat treatment and could be more than one hundred times higher than the control group. When the temperature cycle increased from $27^{\circ} \mathrm{C}$ to $39^{\circ} \mathrm{C}$, the expression level of $s m h s p$ did not increase, but decreased on Day 2 or Day 3. With respect to comparisons of gene expression of $h s p 70, h s p 90$ and $s m h s p$, we found that the transcription level of $\operatorname{smhs} p$ was much higher than that of $h s p 70$ and $h s p 90$ under the same heat stress. Thus, smhsp may play an important part in response to heat stress in rice flag leaves. During the heat treatment cycle, the expression level of $s m h s p$, hsp70 and hsp90 genes always changed with the trend of temperature, but the changes became smaller over time. The maximum expression values appeared on Day 2 or Day 3. The time points of Day 2 and Day 3 might be the key points for II YOU 838 responses to high temperature.

\section{Expression of SOD, POD and CAT genes after heat treatment}

We compared the expression of SOD, POD and CAT genes between samples of the heat treatment group and the control group over four days at $27{ }^{\circ} \mathrm{C}$ (sampled at 08:00 h) and $39{ }^{\circ} \mathrm{C}$ (sampled at 16:00 h) by quantitative real-time RT-PCR. The results were normalized by the mean for the reference genes actin1 and $18 s \mathrm{r} N A$. The normalized expression of SOD, POD and $C A T$ genes were significantly increased after heat treatment (Fig. 2). They were notably higher than the control group samples and the samples prior to the imposition of heat stress, except for SOD in the $39^{\circ} \mathrm{C}$ heat treatment group on Day 4 . The expression of of SOD under $39{ }^{\circ} \mathrm{C}$ was significantly lower than that under $27^{\circ} \mathrm{C}$ on Day $4(p<0.05)$. When the temperature cycle increased from $27^{\circ} \mathrm{C}$ to $39^{\circ} \mathrm{C}$, the expression level of $S O D$ decreased on Day 4. There were no significant differences in the expressions of SOD, POD and CAT genes among the control group over four consecutive days $(p<0.05)$. After heat treatment, the expression of $S O D$ and POD under $39{ }^{\circ} \mathrm{C}$ on Day 2 were the highest of any other heat treatment group samples at this temperature. The expression of $C A T$ under $39^{\circ} \mathrm{C}$ on Day 3 was 
the highest of any other heat treatment group samples. The expression of $P O D$ and $C A T$ genes still increased significantly until the Day 4. The expressions of $P O D$ and $C A T$ were very consistent with the change of temperature. It could be deducing that the $S O D$ was involved in early responses to heat, and the $C A T$ and $P O D$ were involved in later responses to heat in the rice flag leaf. The time points of Day 2 and Day 3 might be the important transition for II YOU 838 responses to high temperature. During the heat treatment cycle, the expression levels of $S O D, P O D$ and $C A T$ changed with temperature, but the change range became smaller with time. Thus, the three antioxidant protective enzyme genes appeared to be sensitive to the high temperature.

\section{Discussion}

Heat stress is a major abiotic stress limiting rice growth and yield in many areas of the world. Rice hybrids have shown resistance to high temperatures, which may be due to heterosis to some extent (Hochholdinger and Baldauf 2018). To overcome the challenges presented by global warming, it is important to understand how rice hybrids perceive and respond to high temperatures. II YOU 838 is a hybrid rice which was developed by irradiation mutation breeding of Fu Hui 838 (male parent) and II-32A (female parent). As a hybrid, II YOU 838 has notable resistance to high temperatures (Su et al. 2013; Wang et al. 2016; Wang et al. 2015). The field identification results showed that seed set and yield are highest in II YOU 838 compared to its parents under natural high temperature stress. The heat tolerance of II YOU 838 may be also associated with heterosis.

We performed expression analysis of smbsp, hsp70, hsp90, SOD, $P O D$ and $C A T$ genes in II YOU 838 by quantitative real-time RT-PCR in response to different heat stress to analyze the connection between heat resistance /injury and expression of these 6 genes. The results showed that the expression of $s m b s p$, hsp70, hsp90, SOD, POD and CAT genes responded to the different heat-stress intensities. The smbsp, hsp70, bsp90, SOD, $P O D$ and $C A T$ genes were very sensitive to temperature changes during the long-term heat stress. Based on these findings, we propose these genes as potential heat resistance molecular biomarkers in the control of heat stress response.

The expression analysis of $h s p 70, b s p 90$ and smbsp in II YOU 838 rice flag leaves under heat treatment revealed that the HSP family genes are activated and available to play protective roles in rice cells. The expression of the smbsp gene had the largest change under a range of heat stress treatments within four days. It is consistent with previous studies in that the heat-responses of smHSPs were remarkably and continuously elevated during heat shock, and may work efficiently in heat stress response in rice flag leaf (Jagadish et al. 2010; Lee et al. 2010; Zhang et al. 2013). The data demonstrated that the expression of smbsp increased after a night of recovery and increased more with the accumulation of heat stress days. It suggested that it may play a significant role in the cellular recovery mechanism by regulating the level of transcription in rice after heat stress.

Most HSP90 and HSP70 family genes were significantly upregulated under early heat treatment (Hahn and Scharf 2011; Zhang et al. 2013), which is similar to the expression pattern in the rice panicle (Zhang et al. 2012). The protective HSP70 and HSP90 had elevated levels of protein and gene expression after heat treatment in wild rice (Scafaro et al. 2010). Earlier studies in a range of species, showed that HSP70 protein interacts with unfolded proteins (Bhattacharya et al. 2009) and this is crucial for the survival of bacteria, yeast and plants under stress conditions (Mogk et al. 2008). The investigation suggested that mitochondrial HSP70 may suppress programmed cell death in rice protoplasts by inhibiting the amplification of ROS (Qi et al. 2011). OsHsp90 from rice when expressed in E. coli maintained its growth at hydroperoxides to harmless molecules (Ighodaro and Akinloye, 2017).

The expression of $h s p s$ and antioxidant enzyme genes had initially alleviated some of the heat stress in rice. Then the expression of hsps and antioxidant enzyme genes tend to decline after the maximum during the four consecutive days of heat treatment. There was a threshold between Day 2 and Day 3 under long-term heat stress. These time points might be the transition and key points for II YOU 838 responses to high temperature. The crop's response to heat stress is associated with a complex molecular genetic regulatory network. The difference in $s m b s p$, $h s p 70, b s p 90$, SOD, POD and CAT expressions, might lead to different functions in rice under heat stress. This fueld further research on the transcriptional changes of $s m b s p, h s p 70, h s p 90, S O D, P O D$ and $C A T$ genes in response to heat stress in rice. Although the expression of smbsp, hsp70, hsp90, SOD, POD and CAT responded to different heat-stress intensities, the transcription of these six genes was limited. However, it should be a focus of the further investigation of their possible application in the improvement of heat tolerance in rice. high temperatures (Liu et al. 2009). In contrast, over-expression of AtHsp90.3 impaired plant tolerance to heat stress, which suggested that proper homeostasis of HSP90 is critical for cellular stress response and /or tolerance in plants (Xu et al. 2010). Compared with the wild type, the OsHsp90 family gene-overexpressing plants had significantly higher SOD activity, which probably acts through the modulation of ROS homeostasis in response to abiotic stresses (Xiang et al. 2018). It could be deduced that the HSP90 and HSP70, which modulated the ROS homeostasis, are involved in a versatile regulatory regime for the early responses to heat stress in the rice flag leaf. As the first enzyme in the detoxifying process, the $S O D$ gene was greatly up regulated at the early stage of heat stress (Asada 1999). SOD may play a central role in the regulation of total SOD activity and ROS detoxification in rice anther as affected by high temperature exposure at meiosis stage (Zhao et al. 2018). The expression of $P O D$ genes is regulated in response to biotic and abiotic stresses as well as during plant development (Andréia et al. 2012). It implicates peroxidases as key players during the whole life cycle of a plant, and particularly in cell wall modifications, in roles that can be antagonistic depending on the developmental stage (Passardi et al. 2004). This diversity of functions derives in part from two possible catalytic cycles of peroxidases involving the consumption or release of $\mathrm{H}_{2} \mathrm{O}_{2}$ and reactive oxygen species. CAT, a major peroxisome protein, plays a critical role in removing peroxisome-generated reactive oxygen species (ROS) produced by peroxisome enzymes (Lee et al. 2018). SOD, POD and CAT are efficient in neutralizing any molecule with the potential of developing into a free radical or any free radical with the ability to induce the production of other radicals. These enzymes dismutate superoxide radical, and breakdown hydrogen peroxides, respectively.

\section{Materials and Methods}

\section{Samples, heat stress and flag leaf collection}

II YOU 838 rice plants were transplanted from the experimental field in Sichuan Institute of Atomic Energy in China to controlled environment cabinets (PGX-300B light incubator). The rice plants were grown in a growth chamber under the conditions of $600 \mu \mathrm{mol} \mathrm{m} \mathrm{m}^{-2} \mathrm{~s}^{-1}$ artificial illumination $(13 \mathrm{~h}$ photoperiod) and $75 \%-80 \%$ humidity. Temperature stresses were applied during rice anthesis, the daily average temperature was $34^{\circ} \mathrm{C}$ (the temperature cycle was 08:00-10:00 at $35^{\circ} \mathrm{C} ; 10: 00$ $-12: 00$ at $37{ }^{\circ} \mathrm{C} ; 12: 00-19: 00$ at $39{ }^{\circ} \mathrm{C} ; 19: 00-21: 00$ at $37{ }^{\circ} \mathrm{C} ; 21: 00$ $-24: 00$ at $34{ }^{\circ} \mathrm{C} ; 24: 00-03: 00$ at $30{ }^{\circ} \mathrm{C} ; 03: 00-08: 00$ at $\left.27{ }^{\circ} \mathrm{C}\right)$. The control group was maintained at a constant $27^{\circ} \mathrm{C}$. The heat treatment group and control group had the same light intensity, humidity, water and fertilizer conditions.

The flag leaves of II YOU 838 rice were harvested during anthesis at 08:00 and 16:00 over four consecutive days. They were at 08:00 minimum temperature of $27{ }^{\circ} \mathrm{C}$ and at16:00 maximum temperature of $39{ }^{\circ} \mathrm{C}$. The heat treatment group and the control group flag leaves were collected at the same time, 
Table 1. The Primers were used in quantitative real-time RT-PCR analysis.

\begin{tabular}{|lllll|}
\hline Target & Forward primer $\left(5^{\prime}-3^{\prime}\right)$ & Reverse primer $\left(5^{\prime}-3^{\prime}\right)$ & $\begin{array}{l}\text { Product length } \\
(\text { bp })\end{array}$ & $\begin{array}{l}\text { Annealing } \\
\text { temperature }\left({ }^{\circ} \mathbf{C}\right)\end{array}$ \\
\hline actin-1 & GAACTGGTATGGTCAAGGCTG & ACACGGAGCTCGTTGTAGAAG & 250 & $\mathbf{5 8}$ \\
\hline $\begin{array}{l}\mathbf{1 8 s} \\
\text { rRNA }\end{array}$ & CGTCCCTGCCCTTTGTACAC & CGAACACTTCACCGGATCATT & 65 & $\mathbf{5 8}$ \\
\hline HSP70 & CATCTTCTCAATCTCCTCCTTGCT & GCTCCCAGGGGTGTTCCA & 95 & $\mathbf{6 4}$ \\
\hline HSP90 & ACTGCTCGTCGTCGTTGTGC & GCTCGCTGCTGGTGCTGA & 100 & $\mathbf{6 0}$ \\
\hline smHSP & ACAAACCAGGCCAAAGCGAAAA & TCCCCGACAACGCCAAGC & 90 & $\mathbf{7 0}$ \\
\hline SOD & CCCTTTCCACTCGCTCCG & GGTGACGACTCCCTCAACCTG & 133 & $\mathbf{5 8}$ \\
\hline POD & GTGCTGCTCAGCTCCACCG & CAGCTTCGCCTTCACCC & 103 & $\mathbf{7 0}$ \\
\hline CAT & CATCCAGACCATCGACCCC & TGAGCACCATCCTCCCCAC & $\mathbf{1 1 6}$ & $\mathbf{6 7}$ \\
\hline
\end{tabular}
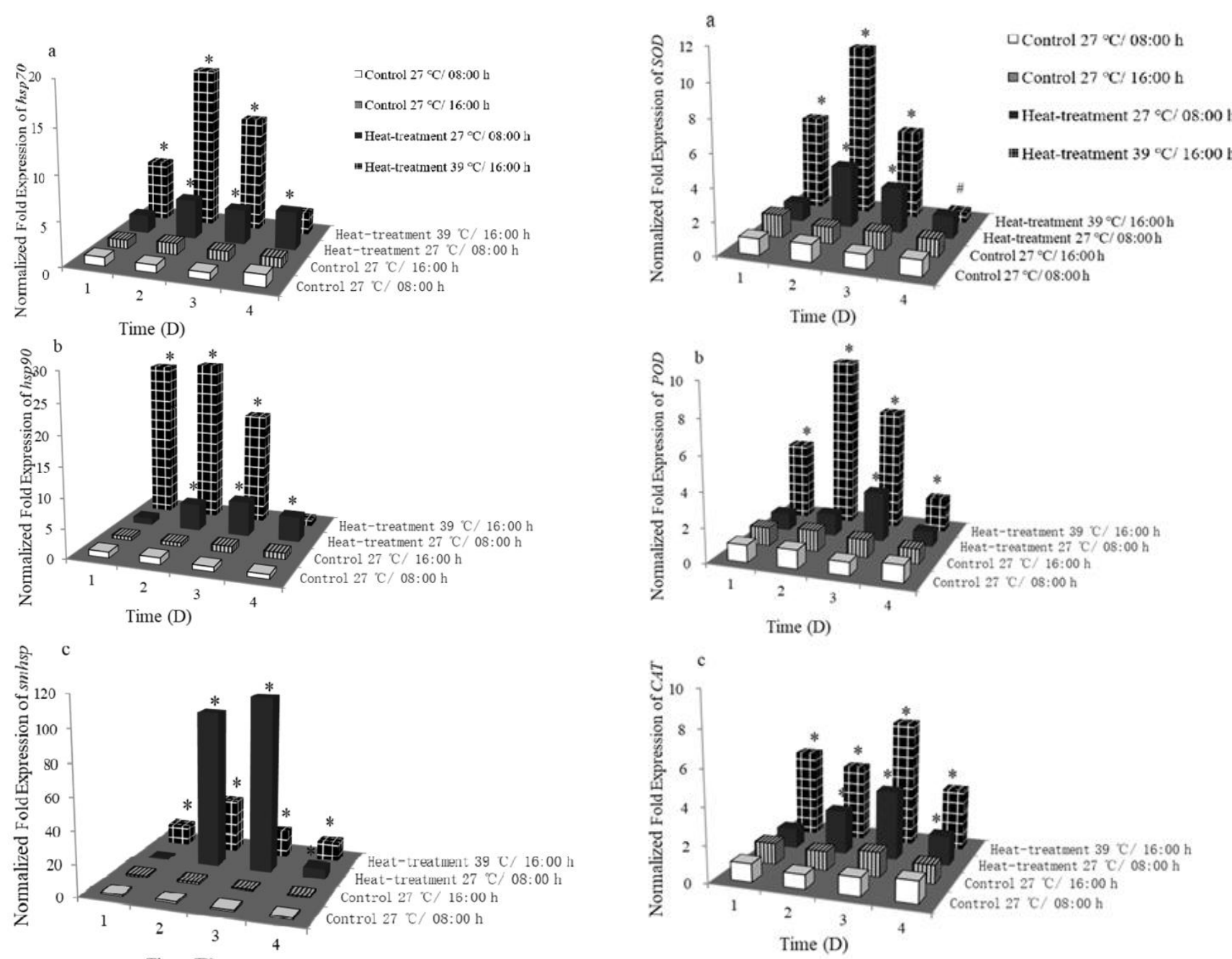

Time (D)

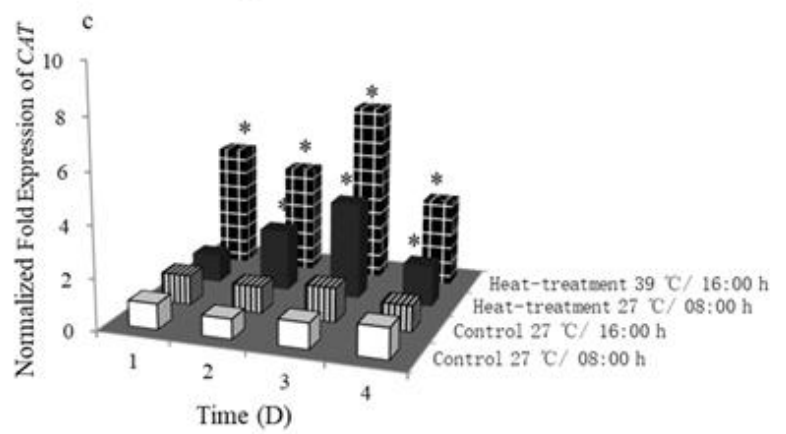

Fig 1. Mean normalized fold expression levels for heat-shock protein genes. Mean normalized fold expression levels for hsps under $27{ }^{\circ} \mathrm{C}$ at $08: 00$ and $39{ }^{\circ} \mathrm{C}$ at $16: 00$ between the heat treatment group and the control group over four consecutive days, normalized by the geometric mean for the reference genes. a. $b s p 70$, b. $b s p 90$, c. smbsp. The data are the means \pm standard deviations, $\mathrm{n}=3$. Date with the "** makers were significantly different $(\phi<0.05)$ as the heat treatments compared with the controls on the same day.

Fig 2. Mean normalized fold expression levels for $S O D, P O D$ and $C A T$ genes. Mean normalized fold expression levels for antioxidant enzyme genes under $27^{\circ} \mathrm{C}$ at $08: 00$ and $39^{\circ} \mathrm{C}$ at 16:00 between the heat treatment group and the control group in four days, normalized by the geometric mean for the reference genes. a. SOD gene, b. $P O D$ gene, c.CAT gene. The data are the means \pm standard deviations, $n=3$. Date with the "** makers were significantly different $(p<0.05)$ as the heat treatments compared with the controls on the same day. 
and were frozen immediately in liquid nitrogen. The process was repeated three times for three batches of rice materials. Flag leaf samples from three independent biological replicates were harvested for RNA isolation.

$R N A$ isolation and quantitative real-time RT-PCR analysis Total RNA was isolated from $100 \mathrm{mg}$ of flag leaf of II YOU 838 using an RNA prep pure Plant Kit (TIANGEN BIOTECH, Beijing, China) as described by the manufacturer. Genomic DNA was eliminated by RNase-free DNase I (TIANGEN BIOTECH, Beijing, China) treatment during the isolation procedure. $2 \mu \mathrm{g}$ RNA was extracted from every sample and reverse transcribed at $37^{\circ} \mathrm{C}$ for $60 \mathrm{~min}$ using a blend of oligo (dT) 15 primer and $100 \mathrm{U}$ of Quant reverse transcriptase and a Quant script RT Kit (TIANGEN BIOTECH, Beijing, China). Gene quantification was performed with a iQTM5 Real Time PCR Detection System (Bio-Rad, U.S.). Primers were designed from GenBank sequences with the aid of Primer-Blast. The sequences of the primers were shown in Table 1. For each gene, three technical replicates and three independent biological replicates were used at each sampling time point.

Each PCR was performed in a RealMasterMix, containing SYBR Green I and $0.5 \mathrm{U}$ of Hotmaster Taq DNA polymerase (TIANGEN BIOTECH, Beijing, China). The final concentrations of primers and $\mathrm{Mg}^{2}$ were $0.5 \mu \mathrm{M}$ and $4 \mathrm{mM}$, respectively. The two internal reference genes, actin-1 and $18 \mathrm{~s}$ $r \mathrm{RN} A$, were used to correct six genes of interest. They are used to eliminate sample-to-sample variation of RNA isolation and reverse transcription (Radonic et al., 2004; Vandesompele et al., 2002). The thermal cycling conditions of $18 s r R N A$, actin- 1 and SOD were as follows: $95^{\circ} \mathrm{C}$ for $2 \mathrm{~min}$; followed by 40 cycles of $10 \mathrm{~s}$ at $95^{\circ} \mathrm{C}, 10 \mathrm{~s}$ at $58^{\circ} \mathrm{C}$, and $15 \mathrm{~s}$ at $68^{\circ} \mathrm{C}$. Data collection was performed during each extension phase. The thermal cycling conditions of other genes were the same with SOD, except the annealing temperature during 40 cycles. The annealing temperature of other genes was showed in Table 1.

After the PCR programme, the fluorescent real-time PCR data of all samples were tested by software tool iQTM5 Optical System Software Version 2.1 (Pfaffl et al., 2002).

\section{Statistical analysis}

The data obtained from real-time PCR analysis were subjected to One-way Analysis of Variance (ANOVA) followed by LSD (L) test to determine differences in the mean values among the treatments. Significance was concluded at $p<0.05(\mathrm{n}=3)$. Statistical analysis was performed using SPSS 17.0 for Windows.

\section{Conclusion}

Quantitative real-time RT-PCR showed significant expression of smbsp, hsp90, hsp70, CAT, SOD and POD in flag leaves under heat stress. The six genes were responsive and differentially to high temperatures. The maximum expression values were observed on Day 2 or Day 3 after beginning of heat stress. These were the critical periods for response of heat stress in II YOU 838 under long-term heat stress. The process is associated with a complex net of regulation of gene expression. It is imperative to gain a better understanding of the molecular basis of heat tolerance as well as the identification of HSPs and antioxidant enzymes for future studies.

\section{Acknowledgment}

This work was in part supported by IAEA's Coordinated Research Project: Climate proofing of food crops (No. 16592). And this work was also in part supported by Chinese projects: Applied Basic Science of Sichuan province (No. 2018JY0531, 18YYJC0284 and No. 2018RZ0045, 2018GZ0003) and Science and Technology Support of Sichuan province (No. 2016SZ0075, No. 2018JY0009 and No. 2018SZ0308).

\section{References}

Andréia C, Gisele P, Silvia Barcellos R, Carolina Werner R, Fernanda L, Márcia MP (2012) Plant responses to stresses: Role of ascorbate peroxidase in the antioxidant protection. Genetics \& Molecular Biology. 35:1011-1019

Asada K (1999) The water-water cycle in chloroplast: Scavenging of Active Oxygens and Dissipation of Excess Photons. Annual Review of Plant Physiology and Plant Molecular Biology. 50:601-639.

doi:10.1146/annurev.arplant.50.1.601

Baniwal SK et al. (2004) Heat stress response in plants: a complex game with chaperones and more than twenty heat stress transcription factors. J Biosci. 29:471-487

Bhattacharya A, Kurochkin AV, Yip GN, Zhang Y, Bertelsen EB, Zuiderweg ER (2009) Allostery in Hsp70 chaperones is transduced by subdomain rotations. Journal of Molecular Biology. 388:475-490 doi:10.1016/j.jmb.2009.01.062

Chandel G, Dubey M, Meena R (2013) Differential expression of heat shock proteins and heat stress transcription factor genes in rice exposed to different levels of heat stress. Journal of Plant Biochemistry and Biotechnology. 22:277-285. doi:10.1007/s13562-012-0156-8

Chen X et al. (2014) Expression and interaction of small heat shock proteins (sHsps) in rice in response to heat stress. BBA - Proteins and Proteomics. 1844:818-828

Chen X, Shi L, Zhu L, Shi J, Xu J (2017) Molecular Evolution Characteristics and Expression Pattern Analysis of the Heat Shock Protein 70(HSP70) Gene Superfamily in Plant. Genomics \& Applied Biology.

Cheng C et al. (2007) An early response regulatory cluster induced by low temperature and hydrogen peroxide in seedlings of chilling-tolerant japonica rice. BMC Genomics. 8:175

Csermely P, Schnaider T, Soti C, Prohaszka Z, Nardai G (1998) The $90-\mathrm{kDa}$ molecular chaperone family: structure, function, and clinical applications. A comprehensive review. Pharmacol Ther. 79:129-168 doi:S0163725898000138 [pii]

Deng D, Chen H, Deng W, Feng L, Yang X, Ma A, Liu M (2009) Development of a Indica rice restorer line FUHUI838 and its derivative lines with strong restoring ability and their utilization. Journal of Nuclear Agricultural Sciences. 23:175179

Grover A, Agarwal M, Katiyar-Agarwal S, Sahi C, Agarwal S (2000) Production of high temperature tolerant transgenic plants through manipulation of membrane lipids. Curr Sci India. 79:557-559

Gupta SC, Sharma A, Mishra M, Mishra RK, Chowdhuri DK (2010) Heat shock proteins in toxicology: how close and how far? Life Sci. 86:377-384 doi:S0024-3205(10)00004-4 [pii]10.1016/j.lfs.2009.12.015

Hahn A, Scharf KD (2011) Crosstalk between Hsp90 and Hsp70 chaperones and heat stress transcription factors in tomato. Plant Cell. 23:741-755

Hietakangas V, Sistonen L (2006) Regulation of the heat shock response by heat shock transcription factors. Topics in Current Genetics. 16:1-34

Hochholdinger F, Baldauf JA (2018) Heterosis in plants. Curr Biol. 28:R1089-R1092 doi:10.1016/j.cub.2018.06.041

Hu W, Hu G, Han B (2009) Genome-wide survey and expression profiling of heat shock proteins and heat shock factors revealed overlapped and stress specific response under abiotic stresses in rice. Plant Science. 176:583-590 doi:10.1016/j.plantsci.2009.01.016

Huang M et al. (2009) Screening and Identification of Heat Tolerance Genes of Hybrid Rice Southwest China. Journal of Agricultural Sciences. 22:1199-1203 
Ighodaro OM, Akinloye OA (2017) First line defence antioxidants-superoxide dismutase (SOD), catalase (CAT) and glutathione peroxidase (GPX): Their fundamental role in the entire antioxidant defence grid. Alexandria Journal of Medicine. S2090506817301550

Jagadish S, Cairns J, Lafitte R, Wheeler TR, Price A, Craufurd PQ (2010) Genetic analysis of heat tolerance at anthesis in rice. Crop Science. 50:1633-1641

Lee DG, Ahsan N, Lee SH, Kang KY, Bahk JD, Lee IJ, Lee BH (2010) A proteomic approach in analyzing heat-responsive proteins in rice leaves Proteomics 7:3369-3383

Lee JN et al. (2018) Catalase inhibition induces pexophagy through ROS accumulation. Biochem Biophys Res Commun. 501:696-702 doi:10.1016/j.bbrc.2018.05.050

Liu D, Lu Z, Mao Z, Liu S (2009) Enhanced thermotolerance of E. coli by expressed OsHsp90 from rice (Oryza sativa L.) Current microbiology 58:129-133

Mogk A, Haslberger T, Tessarz P, Bukau B (2008) Common and specific mechanisms of $\mathrm{AAA}+$ proteins involved in protein quality control Biochemical Society transactions 36:120-125 doi:10.1042/BST0360120

Panaretou B, Zhai C (2008) The heat shock proteins: Their roles as multi-component machines for protein folding Fungal Biology Reviews 22:110-119 doi:10.1016/j.fbr.2009.04.002

Passardi F, Penel C, Dunand C (2004) Performing the paradoxical: how plant peroxidases modify the cell wall Trends in Plant Science 9:0-540

Qi Y, Wang H, Zou Y, Liu C, Liu Y, Wang Y, Zhang W (2011) Over-expression of mitochondrial heat shock protein 70 suppresses programmed cell death in rice FEBS letters 585:231-239

Scafaro AP, Haynes PA, Atwell BJ (2010) Physiological and molecular changes in Oryza meridionalis Ng., a heat-tolerant species of wild rice Journal of experimental botany 61:191-202

Smykal P, Hrdy I, Pechan PM (2000) High-molecular-mass complexes formed in vivo contain smHSPs and HSP70 and display chaperone-like activity Eur J Biochem 267:2195-2207 doi:ejb1223 [pii]

Sottile ML, Nadin SB (2018) Heat shock proteins and DNA repair mechanisms: an updated overview Cell Stress Chaperones:1-13
Su P, Feng H, Chen H, Yang C, Wu X, Huang Q (2013) Influences of Natural High-temperature Stress on Heat Resistance of Rice Southwest China Journal of Agricultural Sciences 26:1387-1391

Wang W, Vinocur B, Shoseyov O, Altman A (2004) Role of plant heat-shock proteins and molecular chaperones in the abiotic stress response Trends Plant Sci 9:244-252 doi:10.1016/j.tplants.2004.03.006

S1360138504000603 [pii]

Wang Y, Gao P, Fu Y, He J, Sun Q, Huang M (2016) Identification of Heat Resistance in Radiation Breed Hybrid Rice II YOU 838 Hubei Agricultural Sciences:6061-6066

Wang Y, Gao P, Huang M, Chen H, Yang Z, Sun Q (2015) Effects of High Temperature on the Activity and Expression of Antioxidative Enzymes in Rice Flag Leaves during the Flowering Stage Plant Science Journal 33:355-361

Xiang J, Chen X, Wei H, Xiang Y, Yan M, Wang J (2018) Overexpressing heat-shock protein OsHSP50.2 improves drought tolerance in rice Plant Cell Reports 37:1585-1595

Xu X, Song H, Zhou Z, Shi N, Ying Q, Wang H (2010) Functional characterization of AtHsp90.3 in Saccharomyces cerevisiae and Arabidopsis thaliana under heat stress Biotechnol Lett 32:979-987 doi:10.1007/s10529-010-0240-x

Young JC, Moarefi I, Hartl FU (2001) Hsp90: a specialized but essential protein-folding tool J Cell Biol 154:267-273

Zhang X et al. (2012) Expression profile in rice panicle: insights into heat response mechanism at reproductive stage PLoS One 7:e49652 doi:10.1371/journal.pone.0049652

Zhang X et al. (2013) Transcriptome profile reveals heat response mechanism at molecular and metabolic levels in rice flag leaf Gene 530:185-192 doi:10.1016/j.gene.2013.08.048

Zhao Q et al. (2018) Relationship of ROS accumulation and superoxide dismutase isozymes in developing anther with floret fertility of rice under heat stress Plant Physiol Biochem 122:90-101 doi:10.1016/j.plaphy.2017.11.009. 